\title{
Influence of Doping and Annealing on Structural, Optical and Electrical properties Amorphous ZnO Thin Films Prepared by PLD
}

\author{
Azhar AbduAlwahab Ali, K.T. Al-Rasoul, Issam M. Ibrahim \\ Iraqi Ministry of Sciences and Technology, Iraq
}

\begin{abstract}
In this work, ZnO thin films pure and doped with GaO were deposited using pulsed laser deposition (PLD). Technique using a double frequency Q-switching Nd:YAG laser beam $(\lambda=532) \mathrm{nm}$, repetition rate $6 \mathrm{~Hz}$ and the pulse duration $10 \mathrm{~ns}$. After the end of wet mixing and drying process, the $\mathrm{ZnO}: \mathrm{GaO}$ mixtures were pressed to form pellets $(1.3 \mathrm{~cm})$ diameter by using 3 ton pressure and sintered at $1373 \mathrm{~K}$ for $5 \mathrm{~h}$. The product was investigated using XRD. The data of $X$-ray diffraction shows polycrystalline structure, and exhibited hexagonal structure. The film thickness was equal to $300 \mathrm{~nm}$ with rate of deposition of $0.5 \mathrm{~nm} / \mathrm{s}$. ZnO thin films pure and GaO-doped from the pellets with $0.02,0.06$ and 0.1 $w t \%$ of were deposited on glass substrates at room temperature. These films were annealed at different temperatures (373, 473 and 673K). The structural characteristics of the pure and GaO-doped ZnO films show that all the films have amorphous structure at room temperature and $373 \mathrm{~K}$, but when the samples are annealed at 473 and 673K; the XRD detected a hexagonal phase of ZnO. The surface morphology of the deposit materials was studied using atomic force microscope (AFM). The grain size of the particles observed at the surface depended on the annealing temperature. UV-VIS transmittance measurements showed that the films are highly transparent in the visible wavelength region for samples annealed up to $473 \mathrm{~K}$, while at annealing temperature of $673 \mathrm{~K}$ the absorption edge of $\mathrm{ZnO}$ doped with $\mathrm{GaO}$ was shifted to near-infrared region. The optical gap of the films was calculated from the curve of absorption coefficient $(\alpha h \nu)^{2}$ vs. hy and was found to be $3.8 \mathrm{eV}$ at room temperature, and this value decreases from 3.8 to 3.58 $\mathrm{eV}$ with increasing of annealing temperature up to 473-673 K, and increases with the Ga doping. $\lambda_{\text {cutoff }}$ was calculated for $\mathrm{ZnO}$ and showed an increase with increasing annealing temperature and shifting to longer wavelength, while with doping the $\lambda_{\text {cutoff }}$ shifted to shorter wavelength. The photoluminescence (PL) results indicate that the pure $\mathrm{ZnO}$ thin films grown at room temperature show strong peaks at $640 \mathrm{~nm}$, but $\mathrm{GaO}$ doped $\mathrm{ZnO}$ films showed a band emission in the yellow-green spectral region (380 to 450nm).
\end{abstract}

Keywords: thin films, GaO doped $\mathrm{ZnO}, P L D, P L$, electrical conductivity and resistivity

\section{Introduction}

Transparent conducting oxide (TCO) is very important in optoelectronic application, such as solar cell, sensor, and liquid crystal displays. In recent years, the appropriate materials of TCO are $\mathrm{SnO}_{2}, \operatorname{In}_{2} \mathrm{O}_{3}, \mathrm{Sn}: \mathrm{In}_{2} \mathrm{O}_{3}$ (ITO), $\mathrm{Cd}_{2} \mathrm{SnO}_{4}$ [1], and $\mathrm{ZnO}$ [2]. ITO is used usually to be a transparent conducting film [3-5], but the cost of ITO is too high to reduce the price of products which have a TCO film. $\mathrm{ZnO}$ is a semiconductor with a wide direct band gap (3.37 eV) and large exciton binding energy $(60 \mathrm{meV})$. Exciton lasing mechanism from $\mathrm{ZnO}$ films at room temperature was reported recently [6]. Strong room temperature luminescence, high electron mobility, good transparency, etc. are some the advantages of $\mathrm{ZnO}[7,8]$. Wurtzite structured $\mathrm{ZnO}$, a wide band gap semiconductor is a potential candidate for optoelectronics devices [9]. The conductivity of $\mathrm{ZnO}$ without intentionally doping is not high enough as TCO films. Thus, improving the conductivity of $\mathrm{ZnO}$ must rely upon doping elements into $\mathrm{ZnO}$. The group-III elements, such as Al [10-14], Ga [15, 16], and In [17], are usually served as dopants for substituting zinc in order to increase more electronic carriers, then the conductivity can be improved. As doping concentration increased heavily, the amount of electronic carriers are also increased in general. Generally, ZnO films are fabricated by RF magnetron sputtering [18, 19], chemical vapor deposition [20], spray pyrolysis [21, 22] and sol-gel process [23, 24], etc. Among them, pulsed laser deposition [25] technique, metal-organic chemical vapour deposition (MOCVD) [26], arc plasma evaporation [27], dip-coating [28] and ion plating [29]. This outline provides a good context in which is pulsed laser deposition (PLD) can be viewed. PLD is a physical deposition technique: a physical process is used to deposit a vaporized form of the 
material onto a surface (substrate). No chemical reactions are involved. The advantages of pulsed laser ablation are flexibility, fast response, energetic evaporants and congruent evaporation

\section{Experimentation}

$\mathrm{ZnO}: \mathrm{GaO}$ powders were mixed for $2 \mathrm{~h}$ to obtained highly homogeneity samples. The powder then pressed to form a pellet of $1.3 \mathrm{~cm}$ diameter at a pressure of 3 ton, using uniaxial hydraulic press. These pellets were then sintered at $1373 \mathrm{~K}$ for $5 \mathrm{hr}$. The concentrations of added oxide are given in Table 1.

Table 1. The concentration of added oxide

\begin{tabular}{cc}
\hline material $\mathrm{ZnO}$ & Doped with $\mathrm{GaO}$ \\
\hline$(9.998 \mathrm{gm})$ & $0.002 \mathrm{gm}$ \\
$(9.994 \mathrm{gm})$ & $0.006 \mathrm{gm}$ \\
$(9.990 \mathrm{gm})$ & $0.010 \mathrm{gm}$ \\
\hline
\end{tabular}

\section{Results and discussion}

Figure 1 shows the $\mathrm{X}$-ray diffraction pattern of $\mathrm{ZnO}$ thin films prepared by pulsed laser deposition (PLD) technique on glass substrate at room temperature with different annealing temperatures $(373,473 \mathrm{~K}$ and $673 \mathrm{~K})$. There is not evidence of any phase present that means the formation of $\mathrm{ZnO}$ phase weak or amorphous. After annealing-at $673 \mathrm{~K}$ for $(2 \mathrm{hr})$, X-ray diffraction detected a growth of $\mathrm{ZnO}$ on glass. We can be noticed from the $\mathrm{X}$-ray pattern that the peaks at $\left(2 \theta=31.826^{\circ}, 34.481^{\circ}, 36.307^{\circ}, 56.598^{\circ}\right)$ referred to (100), (002), (101) and (110) crystalline planes, respectively. The $\mathrm{X}$-ray diffraction data of thin films coincides with that of the known hexagonal structure. Table (2) shows the experiment and the standard peaks from International Centre for Diffraction Data [Card No. ( \# 96-901-1663 )] of ZnO thin film annealed at $473 \mathrm{~K}$ and $673 \mathrm{~K}$. The grain sizes of the prepared films after annealing $473 \mathrm{~K}$ and $673 \mathrm{~K}$ were calculated using the Scherrer's formula [30]:

$D=k \lambda / \beta \cos \theta$

$D:(G . S)$ is the grain size,

$\mathrm{K}$ : is a constant $(0.94)$

$\lambda$ : is the wavelength of $\mathrm{Cu} \mathrm{Ka}=1.54060\left({ }^{0} \mathrm{~A}\right)$

$\theta$ : is the Bragg's angle

$\beta$ : Full Width at Half Maximum (FWHM)of the preferential plane.

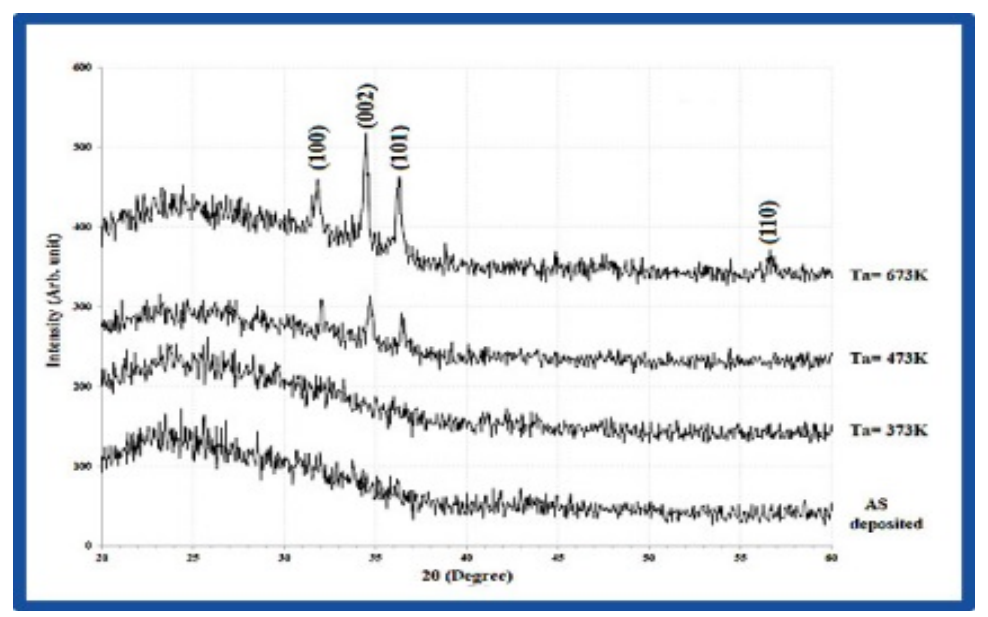

Figure 1. The X-ray diffraction patterns (XRD) of the un-doped $\mathrm{ZnO}$ thin film with different annealing temperature: (a) RT, (b) $373 \mathrm{~K}$, (c) $437 \mathrm{~K}$, (d) $673 \mathrm{~K}$

IJEEI Vol. 3, No. 1, March 2015: $21-29$ 
Table 2. Represent the XRD parameters 20, hkl ,d exp, FWHM and Grain size for doped $\mathrm{ZnO}$

\begin{tabular}{ccccccccc}
\hline $\begin{array}{c}\text { Ta } \\
(\mathrm{K})\end{array}$ & $\begin{array}{c}2 \theta \\
(\mathrm{deg})\end{array}$ & hkl & $\begin{array}{c}\text { FWHM } \\
(\mathrm{deg})\end{array}$ & $\begin{array}{c}\text { Int } \\
(\text { arb. unit })\end{array}$ & $\mathrm{d}_{\text {hkExp }}(\AA)$ & $\begin{array}{c}\mathrm{d}_{\text {hkIStd }} \\
(\AA)\end{array}$ & G.S $(\AA)$ & $\begin{array}{c}\text { uniform } \\
\text { strain*1 }^{-4}\end{array}$ \\
\hline 303 & - & - & - & - & - & - & - & - \\
373 & - & - & - & - & - & - & - & - \\
& 32.033 & $(100)$ & 0.332 & 52.917 & 2.7918 & 2.8137 & 235 & -77.83 \\
473 & 34.730 & $(002)$ & 0.332 & 70.828 & 2.5809 & 2.6035 & 236 & -86.81 \\
& 36.432 & $(101)$ & 0.332 & 55.360 & 2.4642 & 2.4754 & 237 & -45.25 \\
& 31.826 & $(100)$ & 0.539 & 76.526 & 2.8095 & 2.8137 & 144 & -14.93 \\
673 & 34.481 & $(002)$ & 0.290 & 154.681 & 2.5990 & 2.6035 & 270 & -17.28 \\
& 36.307 & $(101)$ & 0.332 & 110.719 & 2.4724 & 2.4754 & 237 & -12.12 \\
& 56.598 & $(110)$ & 0.456 & 35.821 & 1.6249 & 1.6245 & 186 & 2.46 \\
\hline
\end{tabular}

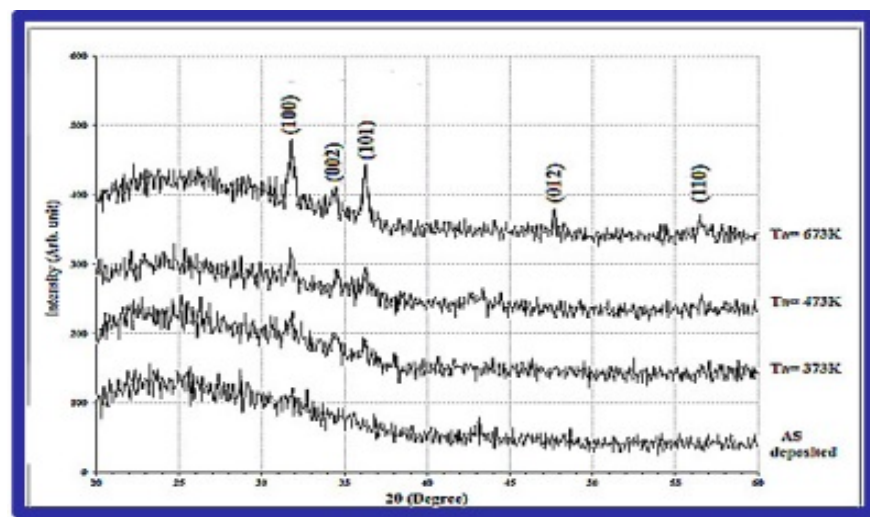

Figure 2. The X-ray diffraction patterns (XRD) of doped $\mathrm{ZnO}$ : Ga thin film with different annealing temperature: (a) RT, (b) $373 \mathrm{~K}$, (c) $437 \mathrm{~K}$, (d) $673 \mathrm{~K}$

Table 3. Represent the XRD parameters $2 \theta$, hkl ,d exp, FWHM and Grain size for Ga doped

\begin{tabular}{|c|c|c|c|c|c|c|c|c|}
\hline \multicolumn{9}{|c|}{$\mathrm{ZnO}$} \\
\hline $\begin{array}{l}\mathrm{Ta} \\
(\mathrm{K})\end{array}$ & $\begin{array}{c}2 \theta \\
(\mathrm{deg})\end{array}$ & hkl & $\begin{array}{l}\text { FWHM } \\
\text { (deg) }\end{array}$ & $\begin{array}{c}\text { Int } \\
\text { (arb. unit) }\end{array}$ & $\mathrm{d}_{\text {hklExp }}(\AA)$ & $\begin{array}{c}d_{\text {hkIStd }} \\
(\AA)\end{array}$ & G.S $(\AA \AA)$ & $\begin{array}{c}\text { uniform } \\
{\text { strain* } 10^{-4}}\end{array}$ \\
\hline 303 & - & - & - & - & - & - & - & - \\
\hline 373 & - & - & - & - & - & - & - & - \\
\hline \multirow{4}{*}{473} & 31.743 & (100) & 0.581 & 61.058 & 2.8167 & 2.8137 & 134 & 10.66 \\
\hline & 34.564 & (002) & 0.373 & 38.263 & 2.5929 & 2.6035 & 210 & -40.71 \\
\hline & 36.224 & (101) & 0.415 & 52.103 & 2.4778 & 2.4754 & 190 & 9.70 \\
\hline & 56.598 & (110) & 0.332 & 32.564 & 1.6249 & 1.6245 & 256 & 2.46 \\
\hline \multirow{5}{*}{673} & 31.784 & (100) & 0.705 & 112.347 & 2.8131 & 2.8137 & 110 & -2.13 \\
\hline & 34.440 & (002) & 0.498 & 51.289 & 2.6020 & 2.6035 & 157 & -5.76 \\
\hline & 36.266 & (101) & 0.456 & 90.366 & 2.4751 & 2.4754 & 173 & -1.21 \\
\hline & 47.676 & (012) & 0.290 & 47.218 & 1.9060 & 1.9110 & 282 & -26.16 \\
\hline & 56.473 & (110) & 0.539 & 38.263 & 1.6282 & 1.6245 & 157 & 22.78 \\
\hline
\end{tabular}

Figure 2 shows the XRD pattern for $\mathrm{ZnO}$ thin films doped with $\mathrm{GaO}$ in $\theta$ range from (20$60^{\circ}$ ), prepared by Pulsed laser deposition (PLD) technique on glass at room temperatures and with different annealing temperatures (373K, $473 \mathrm{~K}$ and $673 \mathrm{~K}$ ). No evidence of any phases present on glass substrate as deposited that means the formation of $\mathrm{ZnO}$ phase is weak or 
amorphous. On the other hand, the XRD patterns of doped $\mathrm{ZnO}$ films with annealing temperature (673K) the structure of these films showed be a polycrystalline. We can be noticed from the X-ray pattern that the peaks at $\left(2 \theta=31.784^{\circ}, 34.440^{\circ}, 36.266^{\circ}, 47.676^{\circ}\right.$ and $\left.56.473^{\circ}\right)$ referred to (100), (002), (101), (012) and (110) direction, respectively. Table 3 shows experimental $(2 \theta)$ shifting for ( $\mathrm{GaO}$ ) and (hkl) for film deposed on glass substrate.

\subsection{Optical Microscopic Examination}

Figure 3 shows the results of microscopic examination (Nikon- Japan) of the $\mathrm{ZnO}$ thin films before and after doping with $\mathrm{GaO}$. Observed before doping the presence of two phases one crystalline of $\mathrm{ZnO}$, and the other for amorphous phase as proved by XRD. In case of doping samples the surface appear clear that mean has less voids and looks smooth and homogenous.

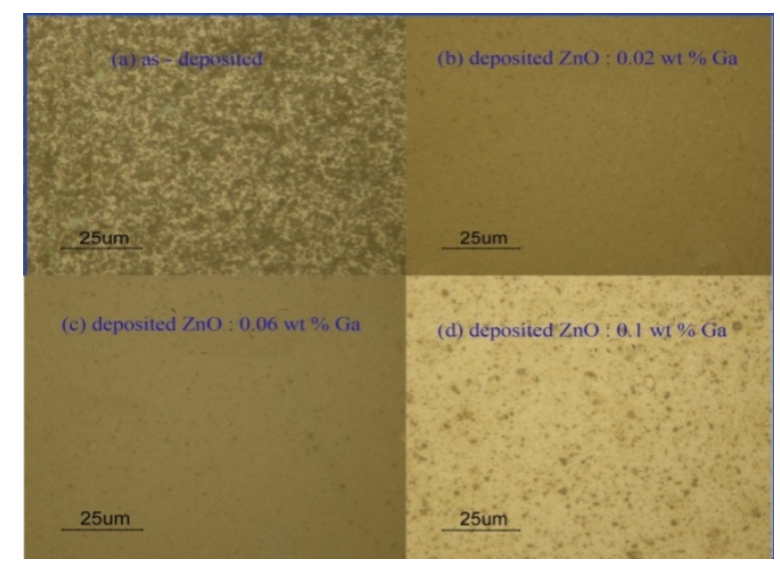

Figure 3. The image of Optical Microscopic of $\mathrm{ZnO}$ thin film. (a) $\mathrm{ZnO}$ without doped, (b) Doped with $2 \% \mathrm{Ga}$, (c) Doped with 0.06 wt\% Ga, (d) Doped with0.1 wt \% Ga

After annealing as show in Figure 4 and 5 observe the effect of annealing on the structural properties, when annealing at $473 \mathrm{~K}$ note smoothing and clearly on the surface membranes, some disappearance of the voids and granular border as well as starts to crystallize and impurities are almost virtually non-existent, while annealing at $673 \mathrm{~K}$ observe the disappearance of the most defects crystal line's improved the crystal structure and the surface becomes more homogeneity and fine.

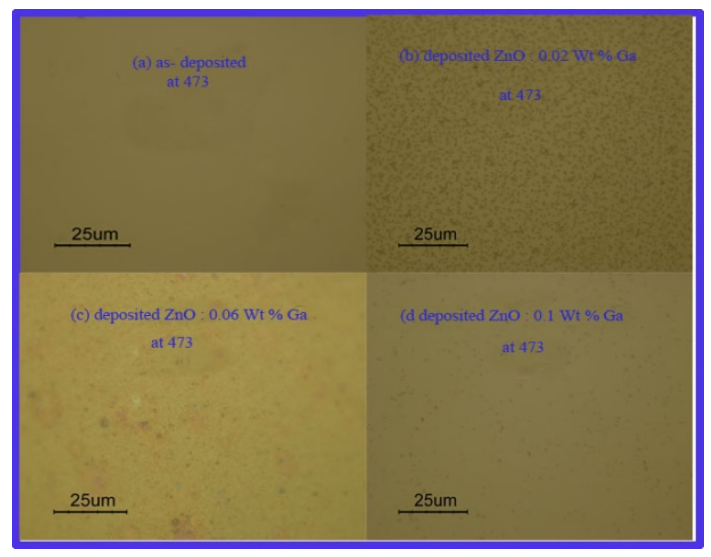

Figure 4. The image of Optical Microscopic of $\mathrm{ZnO}$ thin film annealing at 473K. (a) $\mathrm{ZnO}$ without doped, (b) Doped with 0.02 wt \% Ga, (c) Doped with 0.06 wt\% Ga, (d) Doped with 0.1 wt \% Ga

IJEEI Vol. 3, No. 1, March 2015: $21-29$ 


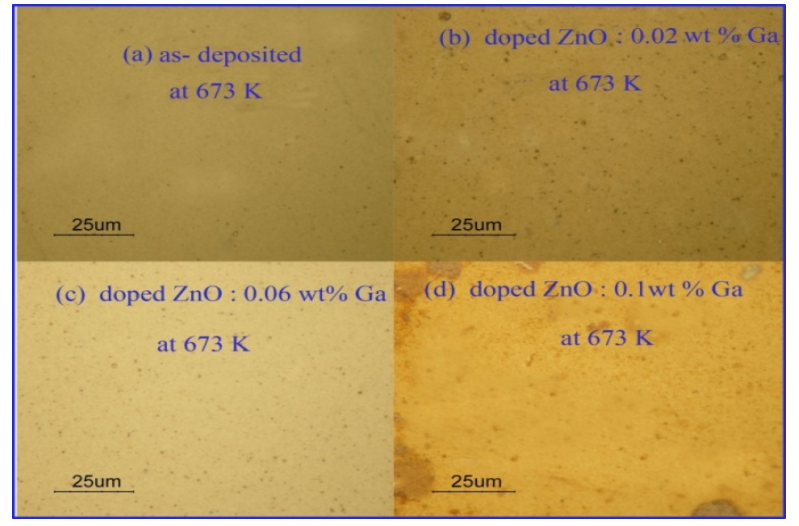

Figure 5. The image of Optical Microscopic of $\mathrm{ZnO}$ thin film annealing at $673 \mathrm{~K}$. (a) $\mathrm{ZnO}$ without doped, (b) Doped with 0.02 wt \% Ga, (c) Doped with 0.06 wt\% Ga, (d) Doped with 0.1 wt \%

\subsection{Atomic Force Microscopy (AFM)}

Figure 6 shows the influence of impurities on the grain size, where the doped leads to the decrease grain which that means with $0.06 \mathrm{wt} \%$ Ga doping the crystalline nature of the film are decreased and also makes the surface more smoother and uniformed. In addition to taking into consideration the influence annealing at $673 \mathrm{~K}$ on the grain size, the annealing cause increased the grain size and crystallized the membranes. Figure 7 shows the crystallization in the film was improved by a sufficient thermal crystallization at $673 \mathrm{~K}$.

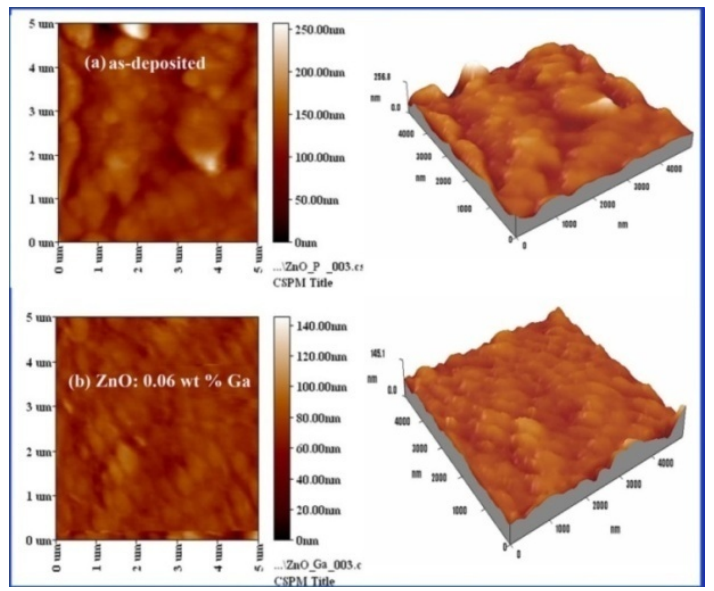

Figure 6. The AFM image of $\mathrm{ZnO}$ thin films at RT. (a) as- deposited, (b) Doped with $0.06 \mathrm{wt}$ $\% \mathrm{Ga}$

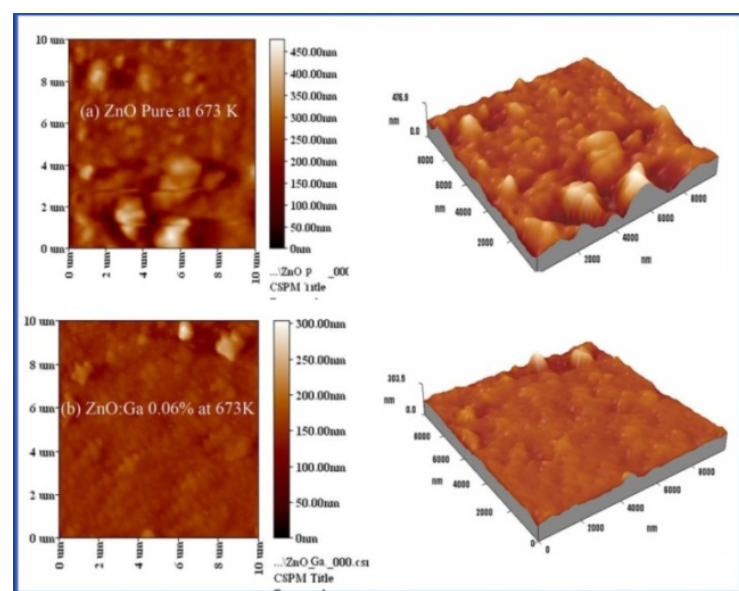

Figure 7. The AFM image of $\mathrm{ZnO}$ thin films annealing at 673K. (a) as- deposited, (b) Doped with 0.06 wt $\% \mathrm{Ga}$

\section{5, Optical Properties of $\mathrm{ZnO}$ films}

The optical properties of the deposited amorphous $\mathrm{ZnO}$ films on glass at room substrate temperature have thickness of (300) $\mathrm{nm}$, at different annealing temperatures ranging from (373673)K doping with different concentration of oxides, have been determined using UV-VIS in the region (200-1200) $\mathrm{nm}$. The properties include the UV-VIS absorption, transmission spectrum have been measured. The optical energy gap is given by Tauc relationship [31].

$$
\text { ahu }=A\left(h u-E_{g}\right)^{n}
$$


Where, $\alpha$ is the absorption coefficient, $A$ is the constant, $h$ is the Planck's constant, $u$ is the photon frequency, $\mathrm{Eg}$ is the optical energy gap and $\mathrm{n}$ is the $1 / 2$ for direct energy gap semiconductors. The optical energy gap decrease with increasing annealing temperature [32, 33], as show in Table 4. The direct energy gap values for amorphous $\mathrm{ZnO}$ pure and doped with different elements of mixed oxides $(\mathrm{GaO})$ for doped is $(0.02,0.06$ and 0.1$)$ wt \% are in the range of $(3.8-4.1) \mathrm{eV}$, as shown in the Figure 8 . It is also observed that the direct energy gap energy inecreases with doping elements. This is presumably because of the effect exerted by the perturbation in the carrier concentration in the conduction band. The $\lambda$ cut off calculate when wavelength $=0$. The $\lambda$ cut off increase shift to short of wavelength with increasing impurities ration [34] as show in Figure 7. The Table 5 explain effect doping on $\lambda$ cut off.

Table 4. Gives the evolution of the band gap with deferent annealing temperature

\begin{tabular}{cc}
\hline Samples & Optical energy gab (eV) (direct) \\
\hline $\mathrm{ZnO}$ at $\mathrm{RT}$ & 3.8 \\
$\mathrm{ZnO}$ at $373 \mathrm{~K}$ & 3.78 \\
$\mathrm{ZnO}$ at $473 \mathrm{~K}$ & 3.7 \\
$\mathrm{ZnO}$ at $673 \mathrm{~K}$ & 3.58 \\
\hline
\end{tabular}

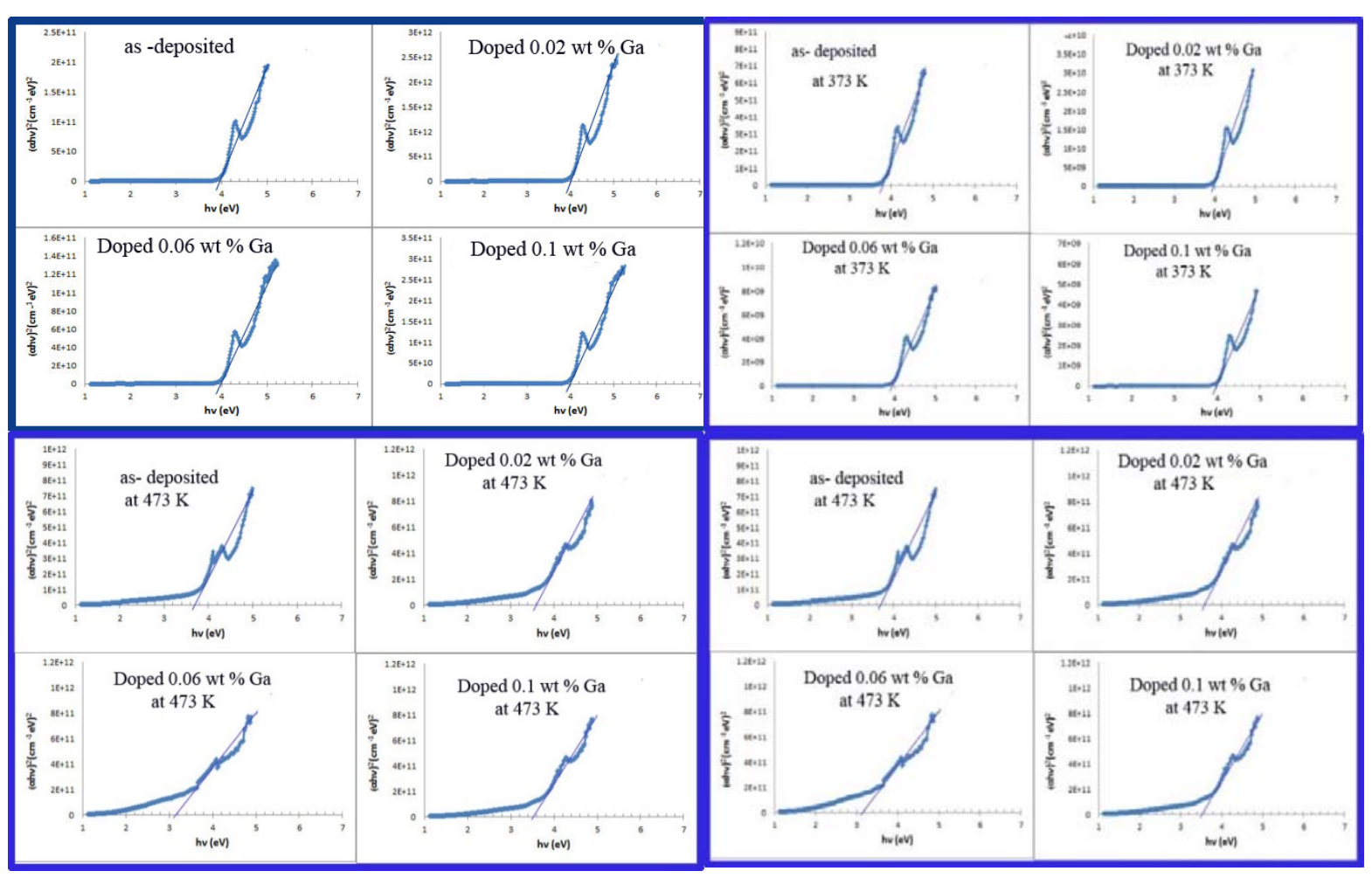

Figure 8. Measurement of energy band gap for $\mathrm{ZnO}$ pure and $\mathrm{ZnO}: \mathrm{Ga}(0.02-0.1 \%)$ thin films

Table 5. $\lambda_{\text {cut off }}$ values of $\mathrm{ZnO}$ undoped and doped thin film with deferent annealing temperature

\begin{tabular}{ccccc}
\hline Type of th film & $\lambda_{\text {cut off }}(\mathbf{n m})$ at RT & $\lambda_{\text {cut off }}(\mathbf{n m})$ at $\mathbf{3 7 3 K}$ & $\lambda_{\text {cut off }}(\mathbf{n m})$ at $\mathbf{4 7 3 K}$ & $\boldsymbol{\lambda}_{\text {cut of }}(\mathbf{n m})$ at $\mathbf{6 7 3 K}$ \\
\hline ZnO pure & 340 & 350 & 350 & 358 \\
ZnO:Ga0.02wt\% & 325 & 330 & 390 & 370 \\
ZnO:Ga0.06wt\% & 320 & 325 & 395 & 380 \\
ZnO:Ga0.1wt\% & 318 & 320 & 360 & 460 \\
\hline
\end{tabular}

IJEEI Vol. 3, No. 1, March 2015: $21-29$ 
Figure 9 and 10 shows the spectral optical transmittance and absorbance as a function of wavelength in the range 200-1200 nm for amorphous $\mathrm{ZnO}$ thin films and doped with different elements of mixed oxides $(\mathrm{GaO})$ of $(0.02,0.06$ and 0.1$) \mathrm{wt} \%$ on glass substrate at room temperature by pulse laser deposition. An increment in the transmittance is observed as the doping oxides were changed from $(\mathrm{GaO})$. The films were found to be highly transmittance in the visible wavelength region. The maximum transmission observed for amorphous $\mathrm{ZnO}$ was almost (70\%)up to $400 \mathrm{~nm}$, while for the doped films, the maximum transmittance equal $(90 \%)$ for $\mathrm{ZnO}: \mathrm{GaO}$ of $(0.1 \mathrm{wt} \%)$.

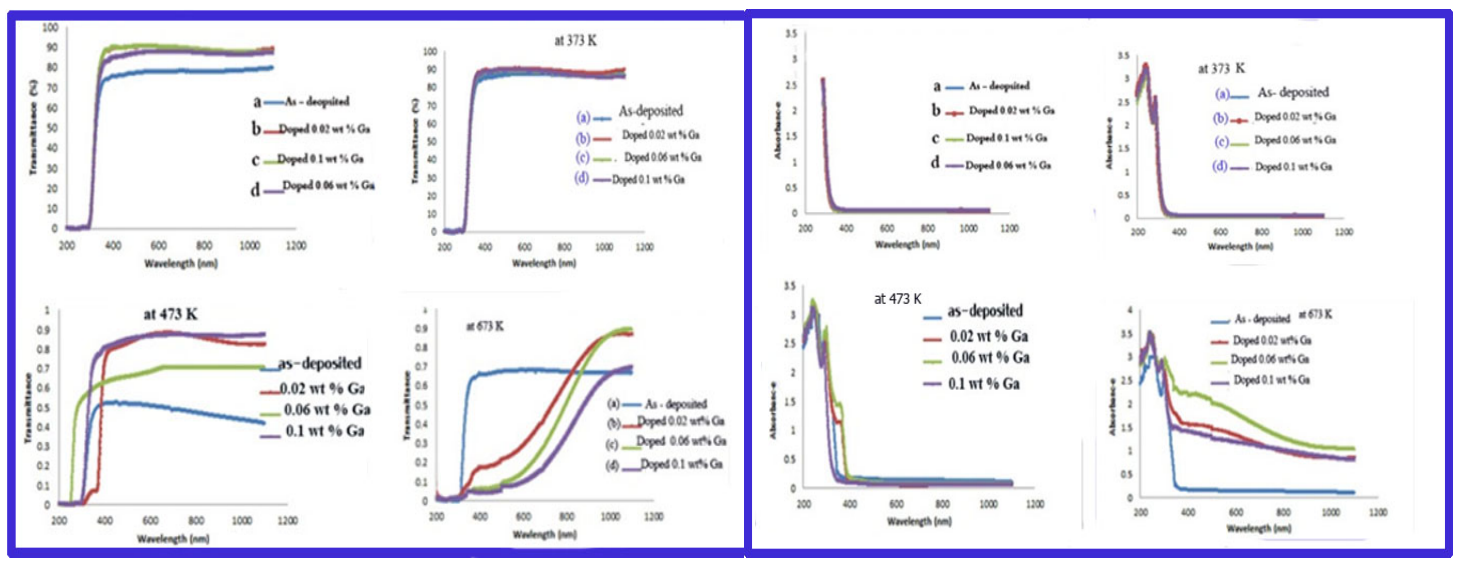

Figure 9. $\mathrm{ZnO}$ and $\mathrm{ZnO}: \mathrm{Ga}(0.02-0.1) \mathrm{wt} \%$ thin films transmittance. a) $\mathrm{ZnO}$ pure, b) $\mathrm{ZnO}$ $0.02 \% \mathrm{Ga}, \mathrm{c}) \mathrm{ZnO} 0.06 \% \mathrm{Ga}, \mathrm{d}) \mathrm{ZnO} 0.1 \%$ $\mathrm{Ga}$ with deferent tempareture
Figure10. ZnO and $\mathrm{ZnO}: \mathrm{Ga}(0.02-0.1) \mathrm{wt} \%$ thin films absorbance. a) $\mathrm{ZnO}$ pure, b) $\mathrm{ZnO}$ $0.02 \% \mathrm{Ga}, \mathrm{c}) \mathrm{ZnO} 0.06 \% \mathrm{Ga}, \mathrm{d}) \mathrm{ZnO} 0.1 \%$ Ga with deferent tempareture

The maximum transmittance observed for amorphous $\mathrm{ZnO}$ deposited at room temperature equal to $(70 \%)$ in the UV region, while for the annealing films. the maximum transmittance equal $(89 \%)$ at annealing temperature $(373 \mathrm{~K})$. The behavior of the transmittance spectra is opposite completely to that of the absorption spectra. In general, we can observe from this figures that transmittance increases with increasing of annealing temperature and this may be due to improving the crystallite size which means a decrease in the absorption. The films were found to be highly transmittance in the visible wavelength region with an average transmittance in excess of $80 \%$. This is probably ascribed to the increase of particle sizes and surface roughness.

The variation of absorption coefficient with wavelength for amorphous $\mathrm{ZnO}$ films deposited on glass substrate at room temperature at different annealing temperatures (373, 473 and 673) $\mathrm{K}$ are shown Figure 11. It is observed that the absorption coefficient decreases with increasing wavelength. This means that direct electronic transition happens. Also, we can notice from this figure that $(\alpha)$ in general increases with the incrase of annealing temperatures

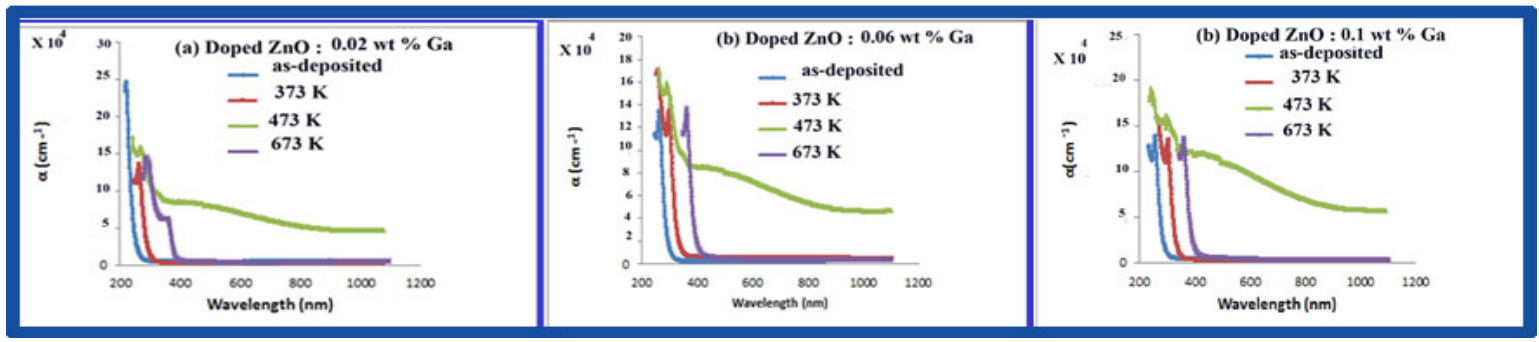

Figure 11. The absorption coefficient $\alpha\left(\mathrm{cm}^{-1}\right)$ vs wavelength $(\mathrm{nm})$ of $\mathrm{ZnO}$ undoped and doped thin films. a) $\mathrm{ZnO} 0.02 \% \mathrm{Ga}$, b) $\mathrm{ZnO} 0.06 \% \mathrm{Ga}$, c) $\mathrm{ZnO} 0.1 \%$ Ga calculate $\lambda_{\text {cut off }}$ values with different temperature 


\section{Conclusion}

Undoped and doped $\mathrm{ZnO}$ with $(\mathrm{Ga})$ oxide films were successfully deposition on glass and silicon substrates by pulsed laser technique and thermally annealed at $(373,473$ and 673)K, states were investigated. All films are semiconducting in nature with n-type conductivity.

The XRD results for undoped, doped and heated samples at $373 \mathrm{~K}$ of $\mathrm{ZnO}$ thin films were amorphous. Thin films exhibit hexagonal crystal structure of undoped $\mathrm{ZnO}$ thin film at $473 \mathrm{~K}$ and $673 \mathrm{~K}$. The intensity of peaks increased with increasing growth temperature at $673 \mathrm{~K}$.

The optical microscopic examination of thin film samples show the disappearance of voids, with smooth and relatively high homogenity, AFM images also support the slow growth of crystallite sizes for the undoped and doped $\mathrm{ZnO}$ and also for the annealed films.

The transmission of undoped $\mathrm{ZnO}$ thin film was found to be above $70 \%$, but higher for other doped one (85-90)\%. After annealing an improvement were found in transmission for both undoped and doped film samples. In case of Samples annealed at $673 \mathrm{~K}$ show low in transmission in UV region for $\mathrm{ZnO}$ thin film doped with $\mathrm{Ga}$. The band gap for as prepaded was $3.8 \mathrm{eV}$, then after annealed at $373 \mathrm{~K}$ slightly decreased to be $3.78 \mathrm{eV}$, then show a value of 3.70 $\mathrm{eV}$ at $473 \mathrm{~K}$ and $3.59 \mathrm{eV}$ at $673 \mathrm{~K}$. The $\lambda_{\text {cut off }}$ increase shift to shorter wavelength with doping, while the $\lambda_{\text {cut off }}$ increase with increasing annealing and shifted to longer wavelength.

$\mathrm{PL}$ emission spectrum from undoped $\mathrm{ZnO}$ thin film has a broad yellow-orange at wave length $(610 \mathrm{~nm})$. For doping $\mathrm{ZnO}$ with $(0.02$ and0.0 6)wt\% Ga have a band emission in yellowgreen regions (380-450)nm, In addition to the first emission(broad yellow-orange) and less intensity. $\mathrm{ZnO}$ doped with $\mathrm{Ga} 0.1 \mathrm{wt} \%$, give high intensity in the region of yellow-orange band, and then vanished at yellow-green band.

\section{References}

[1] R Mamazza Jr, DL Morel, CS Ferekides. Thin Solid Films. 2005; 484(26).

[2] DR Sahu, S Yuan, JL Huang. Microelec. 2007; 38(245).

[3] GH Takaoka, D Yamazaki, J Matsuo. Mat. Chem. Phys. 2002; 74(104).

[4] T Nakaoa, T Nakada, Y Nakayama, K Miyatania, Y Kimura, Y Saitob, C Kaitoa. Thin Solid Films. 2000; 307(155).

[5] H Yumoto, T Inoue, SJ Li, T Sako, K Nishiyama. Thin Solid Films. 1999; 345(38).

[6] ZK Tang, GKL Wong, P Yu, M Kawasaki, A Ohtomo, H Koinuma, Y Segawa. Appl. Phys. Lett. 1998; 72: 3270

[7] DC Look, DC Reynolds, JW Hemsky, RL Jones, JR Sizelove. Appl. Phys. Lett. 1999; 75: 811.

[8] Y Caglar, S Ilican, M Caglar, F Yakuphanoglu. Sol-Gel Sci Technol. 2010; 53: 372.

[9] KJ Kim, YR Park. Appl Phys. 2003; 94: 867.

[10] D Song, J Xia, AG Aberie. Appl. Sur. Sci. 2002; 195: 291.

[11] DC Altamirano-Juarez, G Torres-Delgado, S Jimenez-Sandoval, O Jimenez-Sandoval. Sol. Ener. Mat. Sol. Cell. 2004; 82: 35.

[12] RF Silva, MED Zaniquelli. Thin Solid Films, 2004; 449: 86.

[13] K Tominaga, T Murayama, I Mori, T Ushiro, T Moriga, I Nakabayashi. Thin Solid Films. 2001; 386: 267.

[14] MA Martinez, J Herrero, MT Gutierrez. Sol. Ener. Mat. Sol. Cell. 1997; 45: 75.

[15] JD Ye, SL Gu, SM Liu, YD Zheng, R Zhang, Y Shi. Appl. Phys. Lett. 2005; 86: 192111.

[16] JD Ye, SL Gu, S Zhu, SM Liu, YD Zheng, R Zhang, Y Shi, HQ Yu, YD Ye. Cryst. Grow. 2005; 283: 279.

[17] MT Young, SD Keun. Thin Solid Films. 2002; 410: 8.

[18] Y Zhou, PJ Kelly, A Postill, O Abu-Zeid, AA Alnajjar. Thin Solid Films. 2004; 33: 447-448.

[19] EG Fu, DM Zhuang, G Zhang, M Zhao, WF Yang. Microelectr. 2004; 35: 383.

[20] TM Barnes, J Leaf, C Fry, CA Wolden. Cryst. Growth. 2005; 274: 412.

[21] H Kim, A Pique, JS Horwitz, H Murata, ZH Kafafi, CM Gilmore, DB Chrisey. Thin Solid Films. 2000; 798: 377-378.

[22] SH Mondragon, A Maldonado, A Reyes. Appl. Surf. Sci. 2002; 193: 52.

[23] JH Lee, B O Park, Mater. Sci. Eng. B. 2004; 106: 242.

[24] Y Natsume, H Sakata. Thin Solid Films. 2000; 372: 30.

[25] GG Valle, P Hammer, SH Pulcinelli, CV Santilli. Eur. Ceram. Soc. 2004; 24: 1009.

[26] Kaul AR, Gorbenko OY, Botev AN, Burova LI. Superlatt. Microstruct. 2005; 38: 272.

[27] Minami T, Ida S, Miyata T, Minamino Y. Thin Solid Films. 2003; 445: 268.

[28] Fathollahi V, Amini MM. Mater. Lett. 2001; 50: 235.

[29] Iwata K, Sakemi T, Yamada A, Fons P, Awai K, Yamamoto T, Matsubara M, Tampo H, Niki S. Thin Solid Films. 2003; 445: 274.

[30] Th H DE Keijser, et al. Appl. Cryst. 1982; 15: 308-314.

IJEEI Vol. 3, No. 1, March 2015: $21-29$ 
[31] JI Pankove. Optical Processes in Semiconductors. Prentice-Hall, New Jersey. 1971.

[32] N Tigau, et al. Optoelectronics Adv. Mater. 2004; 6: 449.

[33] M Popa, V Lisca, M Stancu, E Buda, T Pentia. Botila, Optoelectro. Adv. Mater. 2006; 46.

[34] Hayder Mohammad Ajeel. Study effect of annealing Temperature on the structural and optical Properties of CdO Thin Films Prepared by SILAR Deposition Technique. 